\title{
CMEARTICLE \\ Clinics in diagnostic imaging (146)
}

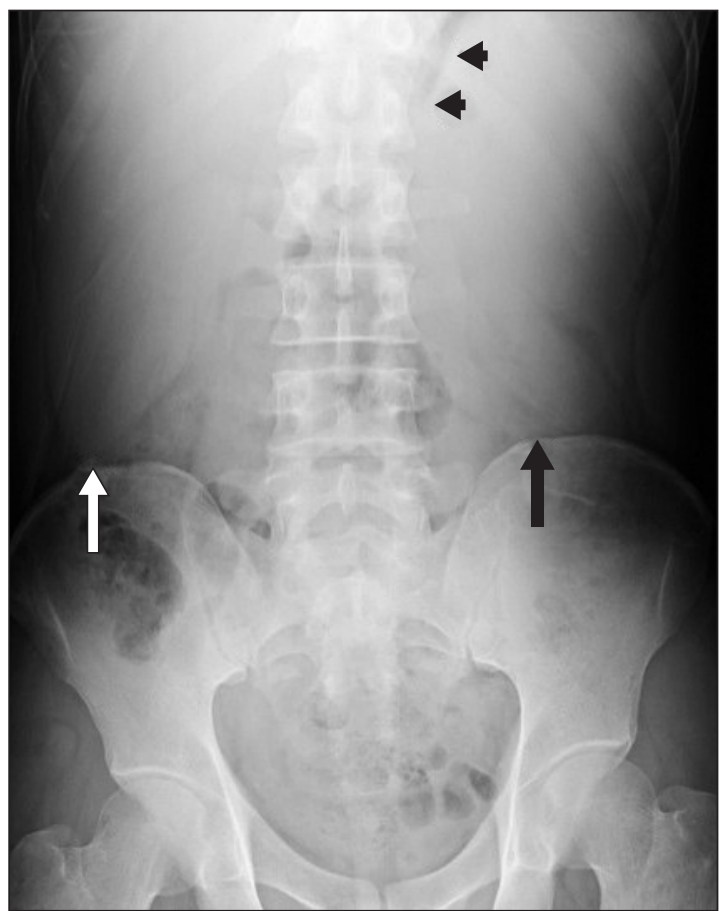

Fig. 1 Radiograph of the abdomen.
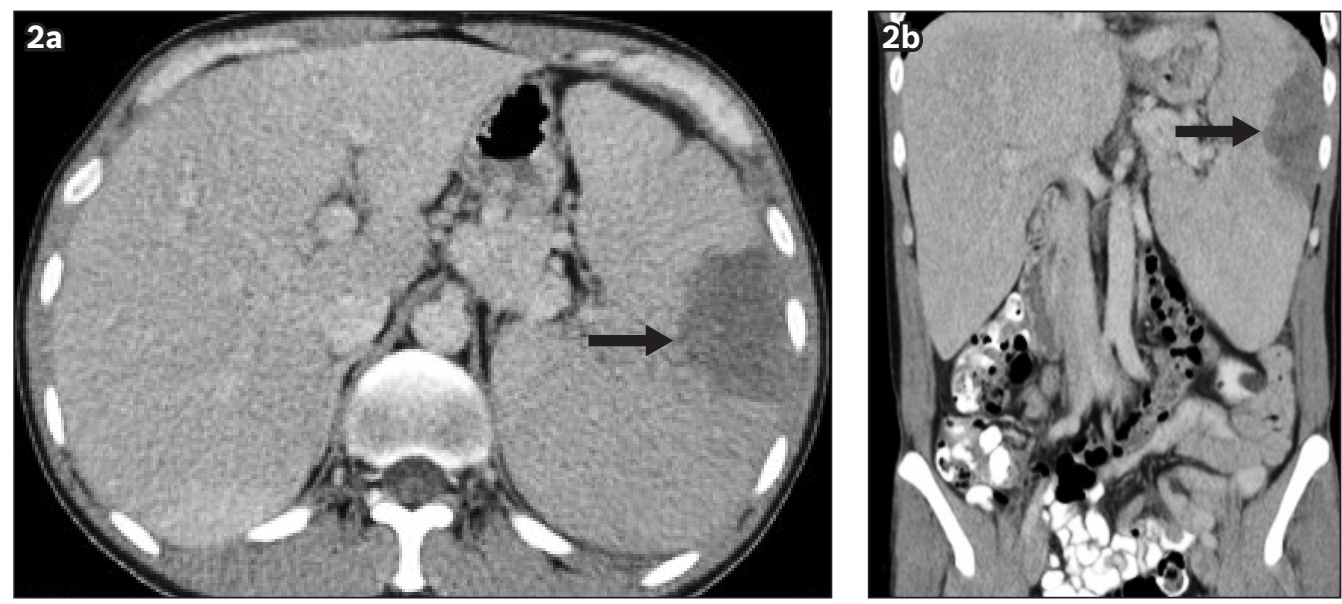

Fig. 2 (a) Axial and (b) coronal CT images of the abdomen and pelvis in the portal venous phase.

\section{CASE PRESENTATION}

A 42-year-old Chinese man who had no significant past medical history presented with a four-day history of left lower chest pain. He had a loss of appetite and weight loss of $4 \mathrm{~kg}$ over the past three months. Physical examination revealed tender splenomegaly, which was palpable $5 \mathrm{~cm}$ below the left costal margin. Full blood count showed total white blood cell count at $14.6 \times 10^{9} / \mathrm{L}$ (neutrophils $83 \%$ ), haemoglobin $(\mathrm{Hb})$ at $20.5 \mathrm{~g} / \mathrm{dL}$ (haematocrit $63.1 \%$ ) and platelets at $354 \times 10^{9} / \mathrm{L}$. Abdominal radiograph (Fig. 1) and computed tomography (CT) of the abdomen and pelvis (Fig. 2) were also performed. What do these images show? What is the diagnosis? 


\section{IMAGE INTERPRETATION}

Abdominal radiograph (Fig. 1) shows medial displacement of the gastric bubble. In addition, there is increased density in both hypochondria, causing inferior displacement of the bowel loops, in keeping with hepatosplenomegaly. Note the lateral margin of the gastric bubble (arrowheads), and the hepatic (white arrow) and splenic (black arrow) tips. Axial (Fig. 2a) and coronal (Fig. 2b) CT images of the patient's abdomen and pelvis show enlargement of the liver and spleen and a wedgedshaped, hypodense area in the periphery of the spleen, which is compatible with an infarct (black arrows), thus confirming the presence of hepatosplenomegaly with splenic infarct.

\section{DIAGNOSIS}

Polycythaemia vera (PV).

\section{CLINICAL COURSE}

Further workup revealed a depressed erythropoietin level of $0 \mathrm{U} / \mathrm{L}$ and heterozygous mutation of the Janus kinase 2 (JAK2) gene, which confirmed the diagnosis of PV. The patient underwent four episodes of venesection in the ward with serial $\mathrm{Hb}$ level monitoring, draining $300-400 \mathrm{~mL}$ of blood each episode. At discharge, his $\mathrm{Hb}$ level was at $18.1 \mathrm{~g} / \mathrm{dL}$ (haematocrit 55.1\%). The patient was scheduled for outpatient haematology follow-up and currently remains well.

\section{DISCUSSION}

PV is a rare haematological disease with panhyperplasia of the bone marrow progenitors, which increases the production of leucocytes, erythrocytes and platelets. The clinical problem largely arises from an increase in erythrocyte mass, resulting in blood hyperviscosity and a prothrombotic state. ${ }^{(1)}$ An Italian study of 1,213 patients found that $20 \%$ of the patients had a thrombotic event as the presenting symptom of PV and $14 \%$ had a thrombotic event prior to the diagnosis of the disease.
Furthermore, a higher prevalence of haematological and nonhaematological malignancies was demonstrated in this group of patients. ${ }^{(1)}$

The diagnostic criteria for PV were first developed in the 1970s by the Polycythemia Vera Study Group, (2) but some of the original criteria have been superseded by newer investigations over the years. ${ }^{(3)}$ The new set of criteria includes JAK2 mutation, which is present in most patients with PV. ${ }^{(3)}$ The World Health Organization's proposed diagnostic criteria for $\mathrm{PV}^{(3)}$ are listed in Table I. Although splenomegaly is a known complication of $\mathrm{PV}$, mild organomegaly in the early phase of $\mathrm{PV}$ is attributed to congestion. In the later course of the disease, especially in the setting of myelofibrosis, massive hepatosplenomegaly can occur as a result of extramedullary haematopoiesis. In addition to splenic infarct, intra-abdominal thrombosis may also result in Budd-Chiari syndrome and bowel infarction, although these are less common. ${ }^{(4)}$ However, these manifestations alone are not specific to PV.

In another patient, a 58-year-old Chinese man who presented with seizures and an $\mathrm{Hb}$ level of $24 \mathrm{~g} / \mathrm{dL}$, unenhanced $\mathrm{CT}$ of the brain at presentation showed dense dural venous sinuses (Fig. 3a). Venous sinus thrombosis was suspected but eventually proven negative on magnetic resonance (MR) venography (Fig. 3b). While the presence of hyperdense dural venous sinuses in the brain visualised on unenhanced CT is well described

Table I. World Health Organization diagnostic criteria for polycythaemia vera $2008 .^{(3)}$

\begin{tabular}{ll}
\hline A1 & $\begin{array}{l}\text { Raised red cell mass (> } 18.5 \mathrm{~g} / \mathrm{dL} \text { for men and }>16.5 \mathrm{~g} / \mathrm{dL} \\
\text { for women) }\end{array}$ \\
A2 & Presence of JAK2 V617F or JAK2 exon 12 mutation \\
B1 & Bone marrow trilineage myeloproliferation \\
B2 & Subnormal serum erythropoietin levels \\
B3 & Endogenous erythroid colony growth
\end{tabular}

Note: The combination of $A 1, A 2$ and any one of $B$ establishes the diagnosis of PV. The combination of $\mathrm{A} 1$ and any two of $\mathrm{B}$ establishes the diagnosis of PV.
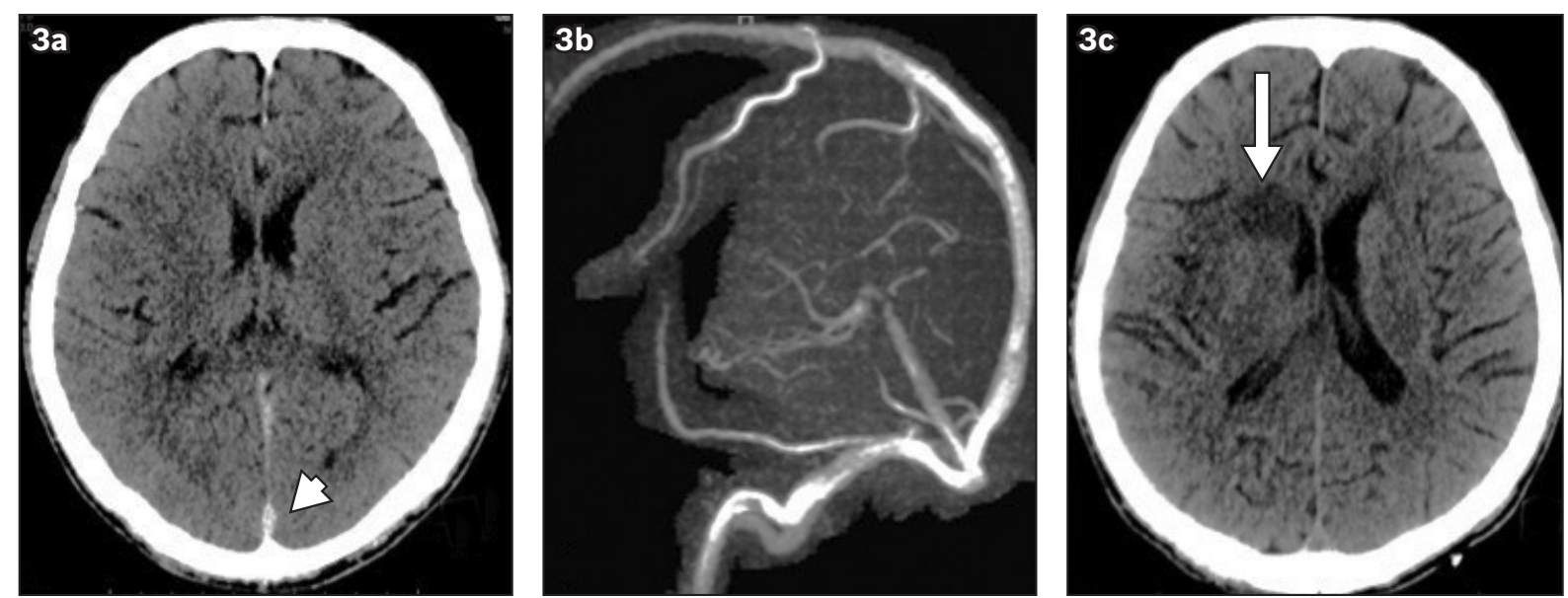

Fig. 3 Imaging study of a 58-year-old Chinese man. (a) Axial unenhanced CT image of the brain performed at presentation (haematocrit level $68.5 \%$ ) shows hyperdensity of the superior sagittal sinus (arrowhead). (b) MR venography performed at presentation shows patency of the dural venous sinuses. (c) Unenhanced CT image of the brain performed three weeks after the initial presentation (haematocrit level $37.8 \%$ ) shows normalisation in density of the superior sagittal sinus. Note the newly established infarct in the territory of the right middle cerebral artery (arrow). 
in case reports of patients with venous sinus thrombosis, the presence of this sign in association with elevated haematocrit levels (but patent venous sinuses) may not be as well known. ${ }^{(5-7)}$ New and Aronow demonstrated a linear correlation between CT attenuation values and haematocrit levels of whole blood preparations, which is largely due to the protein content, and less so to iron content. ${ }^{(8)}$ In the aforementioned patient, imaging clearly demonstrates a reduction in density of the dural venous sinuses, in conjunction with a decrease in haematocrit levels, while the dural venous sinuses remained patent (Fig. 3). Given that PV is a known predisposing factor of venous sinus thrombosis, this is a potential pitfall in the interpretation of CT of the brain in patients with a known background of PV. Therefore, observer awareness is extremely important, and confirmation of the diagnosis with CT venography or MR venography should ideally be performed prior to initiation of therapy.

Thrombotic events and malignancies, which are major causes of morbidity and mortality in patients with $\mathrm{PV}$, are responsible for $36.4 \%$ and $30.0 \%$ of deaths, respectively. Therefore, the objectives of management in patients with $\mathrm{PV}$ are to minimise the risk of thrombotic complications, as well as prevent progression to malignant transformation. ${ }^{(1-3)}$ Management strategy includes a combination of phlebotomy, antithrombotic therapy and judicious use of cytoreductive chemotherapy. ${ }^{(2)}$ As clinical presentation of PV is often nonspecific, hepatosplenomegaly or splenic infarcts may be the only initial radiological presentation. Nevertheless, the presence of an unsuspected thrombotic event should alert the clinician to a possible prothrombotic cause and prompt further investigations to prove otherwise. In the presence of a 'dense sinus' sign on unenhanced CT of the brain, it may be prudent to correlate this imaging finding with the patient's Hb level, as well as conduct further evaluations with CT venography or MR venography.

ABSTRACT A 42-year-old Chinese man presented with left-sided chest pain and splenomegaly. Full blood count revealed erythrocytosis, while plain radiograph and computed tomography of the abdomen and pelvis revealed hepatosplenomegaly with splenic infarction. Further workup confirmed the diagnosis of polycythaemia vera. Clinical and imaging features of polycythaemia vera, as well as the potential pitfalls in image interpretation, are discussed in this article.

Keywords: dural venous sinus thrombosis, erythrocytosis, hepatosplenomegaly, polycythaemia vera, splenic infarct

\section{REFERENCES}

1. Polycythemia vera: the natural history of 1213 patients followed for 20 years. Gruppo Italiano Studio Policitemia. Ann Intern Med 1995; 123:656-64.

2. Campbell PJ, Green AR. Management of polycythemia vera and essential thrombocythemia. Hematology Am Soc Hematol Educ Program; 2005:201-8.

3. Tefferi A. Polycythemia vera and essential thrombocythemia: 2012 update on diagnosis, risk stratification, and management. Am J Hematol 2012; 87:285-93.

4. Aster J, Kumar V. White cells, lymph nodes, spleen, and thymus. In: Cotran RS, Kumar V, Collins T, Robbins SL. Robbins Pathologic Basis of Disease. 6th ed. Philadelphia: Saunders, 1999: 682-3.

5. Healy JF, Nichols C. Polycythemia mimicking venous sinus thrombosis. AJNR Am J Neuroradiol 2002; 23:1402-3.

6. Gayathri S, Prasad A, Sachdeva N, Baruah BP, Aggarwal S. Unique features of polycythemia observed on plain non contrast CT scan of head. J Pediatr Neurosci 2010; 5:27-9.

7. Provenzale JM, Kranz PG. Dural sinus thrombosis: sources of error in image interpretation. AJR Am J Roentgenol 2011; 196:23-31.

8. New PF, Aronow S. Attenuation measurements of whole blood and blood fractions in computed tomography. Radiology 1976; 121(3 Pt. 1):635-40. 


\section{SINGAPORE MEDICAL COUNCIL CATEGORY 3B CME PROGRAMME} (Code SMJ 201305B)

Question 1. Regarding splenomegaly:

(a) It displaces the stomach and bowel loops.

(b) It is specific for polycythaemia vera.

(c) It can result from extramedullary haematopoiesis.

(d) It is usually milder in the setting of polycythaemia vera without myelofibrosis.

Question 2. Regarding polycythaemia vera:

(a) It is a clinical and/or radiological diagnosis.

(b) The presence of JAK2 mutation without erythrocytosis is diagnostic.

(c) Prothrombotic states and malignant degeneration are the main clinical problems in polycythaemia vera.

(d) Bowel infarction is the most common presentation in cases of polycythaemia vera.

Question 3. Polycythaemia vera without myelofibrosis may present with:
(a) Symptomatic anaemia.
(b) Ischaemic stroke.
(c) Splenic infarction.
(d) Budd-Chiari syndrome.

Question 4. The hyperdense dural venous sinus sign visualised on computed tomography (CT) of the brain:

(a) Applies to contrast-enhanced CT imaging.

(b) Is specific to polycythaemia vera.

(c) Is persistent in patients with polycythaemia vera, despite the normalisation of haematocrit levels.

(d) Needs further evaluation with CT or magnetic resonance venography.

Question 5. Regarding the management of polycythaemia vera:

(a) The sole aim of management is to prevent thrombotic complications.

(b) Management includes the use of phlebotomy and cytoreductive chemotherapy.

(c) Antiplatelet drugs are absolutely contraindicated.

(d) Malignant transformation rarely occurs and is not a major concern.

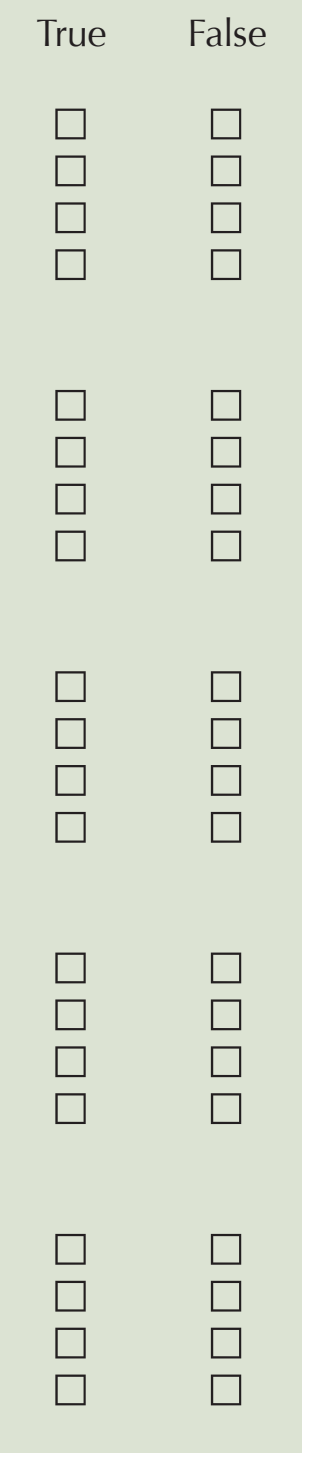

\footnotetext{
Doctor's particulars:

Name in full

MCR number Specialty:

Email address

(1) Log on at the SMJ website: http://www.sma.org.sg/publications/smjcurrentissue.aspx and select the appropriate set of questions. (2) Provide your name, email address and MCR number. (3) Select your answers and click "Submit".

RESULTS:

(1) Answers will be published in the SMJ July 2013 issue. (2) The MCR numbers of successful candidates will be posted online at the SMJ website by 27 June 2013. (3) Passing mark is $60 \%$. No mark will be deducted for incorrect answers. (4) The SMJ editorial office will submit the list of successful candidates to the Singapore Medical Council. (5) One CME point is awarded for successful candidates.

Deadline for submission: (May 2013 SMJ 3B CME programme): 12 noon, 20 June 2013.
} 